\title{
Estimation of fill strength requirements using bonded particle modelling for mining under cemented rockfill
}

\author{
A Turichshev Hatch Ltd., Canada \\ L Cotesta Itasca Consulting Canada Inc., Canada \\ R Brummer Itasca Consulting Canada Inc., Canada \\ M Beauvais Minrail Inc., Canada
}

\begin{abstract}
Recovery of sill pillars is often associated with mining under existing backfill. The backfill stability in such cases is of primary concern due to risks associated with personnel safety, equipment loss, and ore dilution. Two key aspects that control the stability of exposed backfill are the fill strength and the size of the fill exposure. Use of stronger fill will allow for increased excavation size but will come at a higher cost because of higher binder content requirements. A mine operator, therefore, must decide what combination of excavation size and fill strength is appropriate.

In this paper we present the results of a study for a base metal mine in Canada aimed at estimating the strength requirements for cemented rockfill (CRF) being undercut. Numerical simulations utilising bonded particle models were used to relate the size of the undercut to the CRF strength requirements. The results were expressed as the depth of fill failure and as ore dilution, allowing the operator to select appropriate fill strength.
\end{abstract}

Keywords: cemented rockfill, bonded particle modelling, particle flow code (PFC), numerical simulations

\section{Introduction}

Mining under cemented backfill is common in underground mining operations. Recovery of a sill pillar is one example where mining under fill can take place. A sill pillar is a horizontal rock pillar separating two levels or stopes, positioned one above another (Pakalnis \& Hughes 2011). The void above the sill pillar is backfilled after it is mined. When the sill pillar is recovered from below, undercutting of the fill occurs. The backfill becomes exposed above the excavation. Undercutting of backfill requires that the fill remains stable in order to minimise risks associated with personnel safety, equipment loss, and ore dilution. Fill stability, therefore, is of primary concern.

The stability of exposed backfill is determined by the fill strength and the size and shape of the excavation below. With stronger fill in place, a wider excavation can be developed without fill collapsing. Strength of cemented fill is a function of the amount of binder (e.g. cement) used in preparation of the fill. The strength increases as more binder is added, but so does the cost of the fill. In considering excavating under fill, one aims to maximise the width of stable excavation, while attempting to minimise the fill strength and cost. The decision on the combination of the two parameters ultimately rests with the mine operator.

A number of techniques can be used to estimate fill strength requirements. Prior knowledge of fill behaviour is the best tool if the experience is specific to the mining operation. Analytical solutions can be applied, but they are typically only able to address a single mode of failure and require many assumptions (Mitchell 1991). Use of empirical design charts, such as the one illustrated in Figure 1 (Pakalnis et al. 2005), is also common. Empirical charts provide a quick and cost-effective estimate, but rarely match true analysed conditions. Both analytical and empirical methods are acceptable for initial estimates. Use of numerical modelling is another approach. Numerical simulations are capable of addressing some of the shortcomings of the analytical and empirical techniques. 


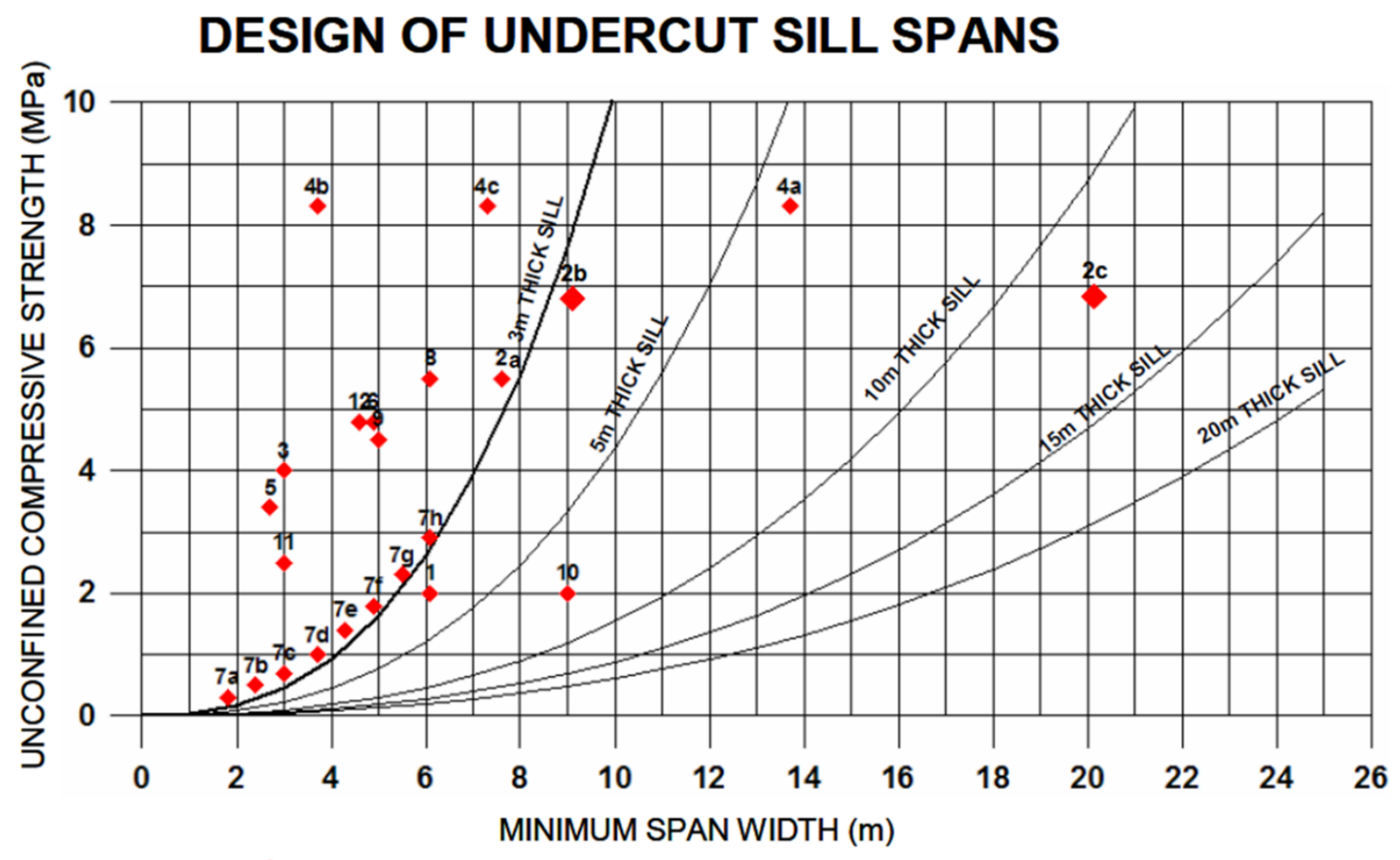

\section{UNDERHAND CUT AND FILL OPERATIONS}

Figure 1 Stability chart for the design of undercut sills with vertical sidewalls with Factor of Safety of 2 (Pakalnis et al. 2005)

With numerical modelling, one uses specialised software designed to simulate mechanical behaviour of rock and backfill under load, including forces and deformations. The backfill behaviour can be modelled by continuous (e.g. finite element, finite difference) or discontinuous (e.g. distinct element) numerical methods (Pakalnis et al. 2005; Brummer et al. 2003; Pierce et al. 2002). A numerical model is capable of addressing multiple failure types that the backfill can exhibit and can reproduce conditions that are specific to the situation being analysed, and, in that respect, it is superior to analytical and empirical design approaches. The trade-offs with using numerical simulations include time required to build and run the models and a steep learning curve in developing skills for use and understanding of the numerical code.

This paper presents results of a study in which bonded particle modelling (BPM) was used to simulate undercutting of stopes filled with cemented rockfill (CRF) at a mining operation. The objective of this work was to advise the mine operator on selecting a panel size for mining under CRF, providing guidelines on expected CRF overbreak and associated dilution for various combinations of fill strengths and panel sizes.

\section{Background information}

The underground base metal mine for which fill stability was studied is located in northwestern Quebec, Canada. The mine produces from several massive sulphide orebodies. The orebody of this study is positioned approximately between 940 and 1,490 m below surface. It has a general dip of approximately $70^{\circ}$ to the south. Figure 2 illustrates the shape of the ore zone. The hanging wall (HW) to footwall (FW) thickness (north-south) of the ore varies between 5 and $35 \mathrm{~m}$. Stopes are designed to be between 5 and 25 $\mathrm{m}$ thick (north-south), $30 \mathrm{~m}$ in height, and $20 \mathrm{~m}$ on strike (east-west). CRF will be used as backfill. Mining under fill, both remote and with man entry, will occur in four areas, including three sill mats and underhand mining in the upper portion of the ore zone. 


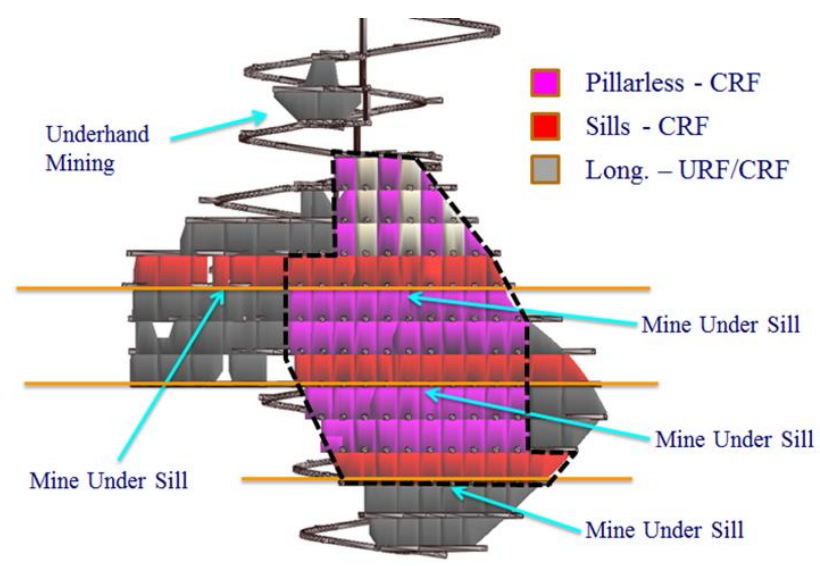

(a)

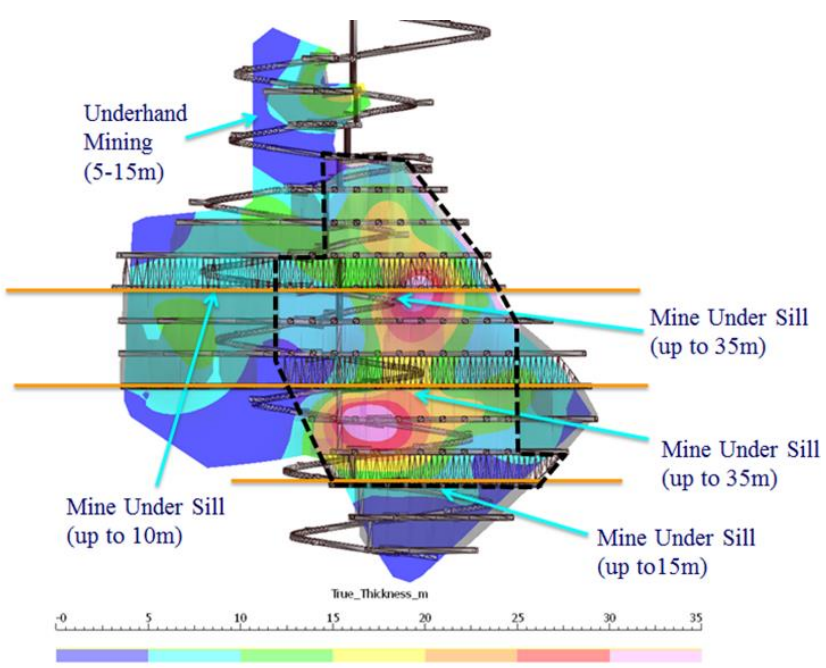

(b)

Figure 2 Long section of the ore zone (looking north), (a) Illustrating mining approaches and backfill types; and, (b) The corresponding distribution of ore thickness

\section{Approach}

Numerical simulations were carried out using BPM, utilising the two-dimensional (2D) version of Itasca's Particle Flow Code (PFC2D) (Itasca Consulting Group, Inc. 2017). The BPM approach was selected because of its unique ability to simulate the behaviour of CRF without its prior specification via a predetermined constitutive law. BPM models allow emergence of material behaviour and manifestation of failure modes as the model computes (Potyondy \& Cundall 2004). The approach had been successfully used in the past to model mining under backfill (Pierce et al. 2002), and significant improvements have been introduced for this work.

PFC2D simulates the material by representing it as an assembly of circular particles that can be bonded to one another, hence forming a bonded particle assembly. The movement and interaction of particles are modelled using the distinct element method (DEM). Particle bonding allows PFC to simulate the behaviour of solid materials such as rock or rockfill.

The particles are rigid and incompressible. The bonds provide resistance to movement and rotation. Bonds fail or break when interparticle forces or moments exceed the bond strengths. As the model progresses, bond-scale damage accumulates, micro-fractures coalesce to form larger fractures, and larger fractures interact to result in macro-scale material failure.

For this work, Flat Joint (FJ) contact model (Itasca Consulting Group, Inc. 2014) was used to simulate the mechanical behaviour of interparticle bonds. FJ model allows particles to be bonded together such that tensile, shear, and bending forces and moments are resisted when the particles displace. When the strength of any part of the bond is exceeded, the bond partially breaks, leading to partial damage. Use of FJ contact model allows PFC material to be calibrated such that both tensile and compressive strengths of the target material are reproduced.

Use of the 2D code allowed for a large number of simulations to be carried out efficiently within the time frame of the project, without sacrificing the quality of the results. Use of 2D modelling was justified based on the geometry of the problem: constant continuous longitudinal geometry of the orebody.

The modelling of CRF behaviour included two stages. In the calibration stage, micro-scale (interparticle) properties were determined such that the target macro-scale behaviour of the fill was replicated. In the second stage, the undercutting of a backfilled stope was modelled. 


\section{$4 \quad$ Calibration of PFC material properties}

PFC material required calibration of its micro-scale properties (interparticle stiffnesses and strength) such that key target macro-scale responses (elasticity, unconfined compressive strength, and tensile strength) of CRF were reproduced by models. The calibration involved performing virtual (numerical) laboratory-type experiments, including direct tension tests for calibration of tensile strength and unconfined and confined (standard triaxial) compression tests for calibration of elasticity and compressive strength.

\subsection{CRF target properties}

CRF compressive strength is a function of the amount of binder (e.g. cement) in the fill mix. The binder content also affects the fill's tensile strength and stiffness. These variations need to be considered by the PFC material.

Table 1 summarises fill properties that were used for calibration of PFC material. The density value was determined based on the results of backfill testing carried out at the mine (Lafarge 2012). The range of the unconfined compressive strength (UCS) values was selected to be within the range of projected strength that CRF can potentially develop (Lafarge 2012). The Young's modulus versus UCS relation was based on the work of Annor (1999). The target Poisson's ratio was based on typical values of CRF. The target tensile strength relation was taken $1 / 10^{\text {th }}$ of UCS, consistent with concrete properties.

Table 1 Target CRF mechanical properties compiled based on published data and experience

\begin{tabular}{ll}
\hline Property & Value \\
\hline Density & $2,100 \mathrm{~kg} / \mathrm{m}^{3}$ \\
UCS & $0.5-6.0 \mathrm{MPa}$ \\
Young's modulus & $0.35 \times \mathrm{UCS}^{1.16}$ \\
Poisson's ratio & 0.3 \\
Tensile strength & $0.1 \times$ UCS \\
\hline
\end{tabular}

\subsection{Calibration results}

As multiple relations among target CRF properties had to be satisfied by a calibrated PFC material, the calibration approach relied on developing multiple calibration models. Six separate fully calibrated models were built. The target CRF parameters for these models are summarised in Table 2. An example of a PFC unconfined compressive strength experiment that was used for calibration of stiffness and strength is illustrated in Figure 3. Similar experiments were used to calibrate material tensile strengths.

Table 2 Macroscopic-scale CRF property sets for PFC material calibration

\begin{tabular}{lllllll}
\hline Property & M1 & M2 & M3 & M4 & M5 & M6 \\
\hline UCS (MPa) & 0.5 & 1.0 & 3.0 & 5.0 & 7.5 & 10.0 \\
Density $\left(\mathrm{kg} / \mathrm{m}^{3}\right)$ & 2,100 & 2,100 & 2,100 & 2,100 & 2,100 & 2,100 \\
Young's modulus (GPa) & 0.16 & 0.35 & 1.25 & 2.26 & 3.62 & 5.06 \\
Poisson's ratio & 0.3 & 0.3 & 0.3 & 0.3 & 0.3 & 0.3 \\
Tensile strength (MPa) & 0.05 & 0.1 & 0.3 & 0.5 & 0.75 & 1.0 \\
\hline
\end{tabular}




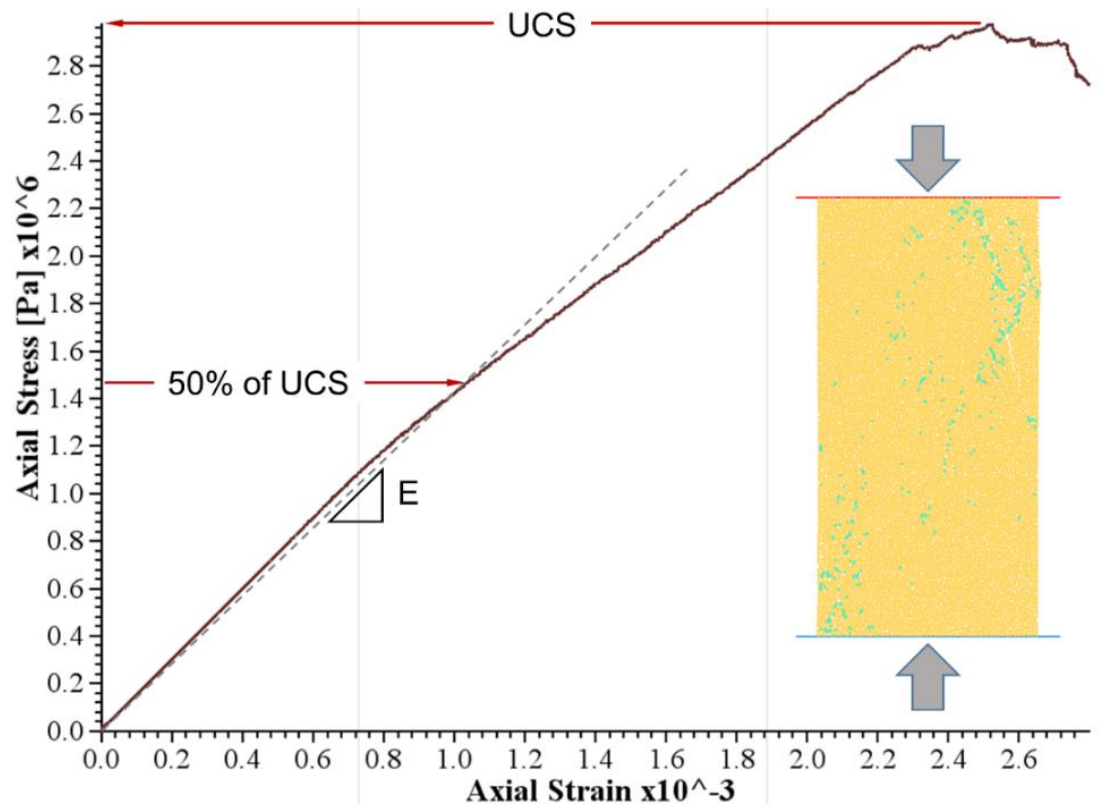

Figure 3 Example of a PFC UCS experiment used to calibrate material properties

Each calibrated model resulted in a set of micro-scale properties. A total of six sets were produced. Using the calibrated property sets, a series of calibration relations were developed, allowing one to generate a set of micro-scale properties to reproduce CRF material of arbitrary target strength. Four key relations are shown in Figure 4.
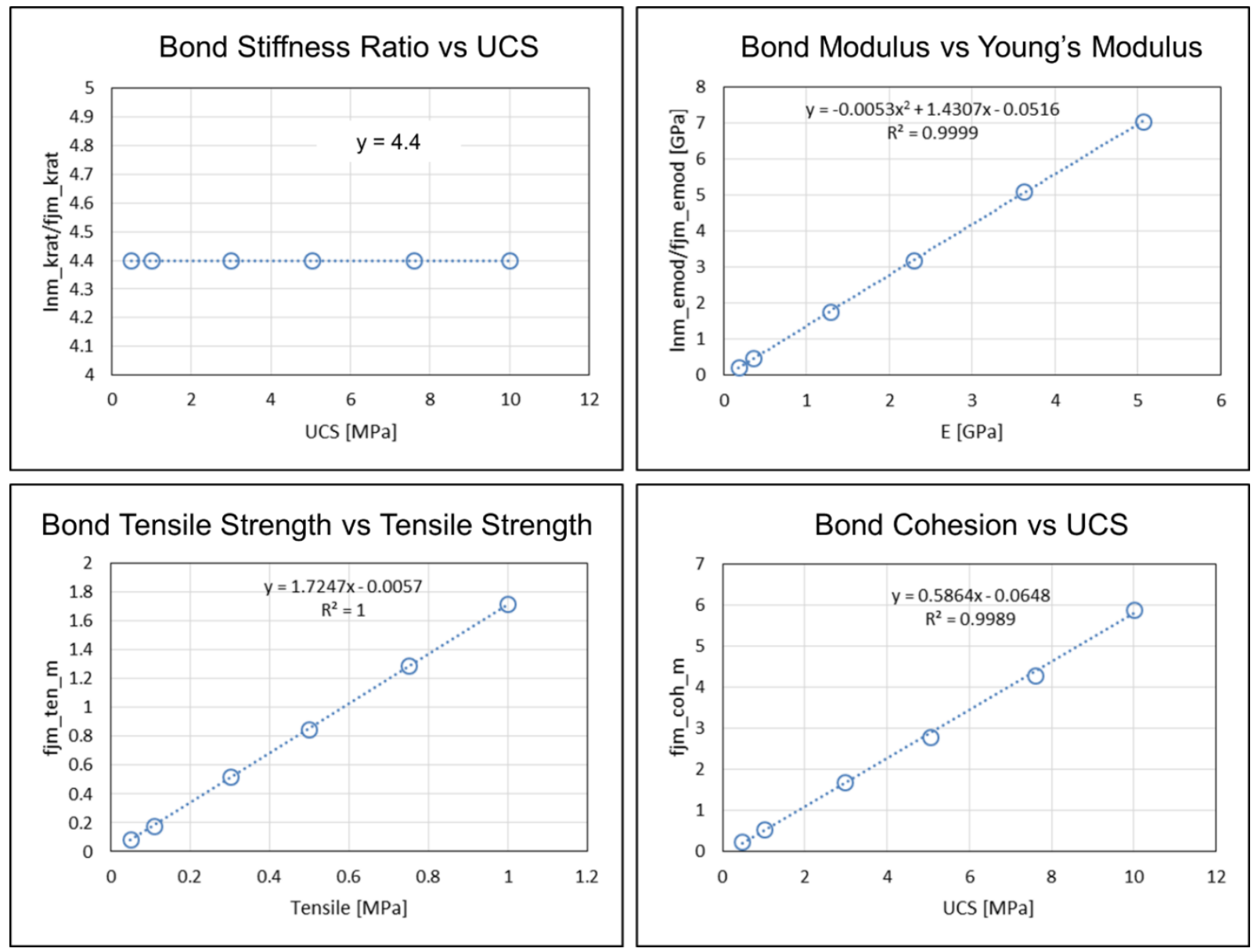

Figure 4 Master relations attained during material calibration. Target fill properties are shown on the $x$-axes, and corresponding micro-scale parameters are plotted along the $y$-axes 


\section{$5 \quad$ Underhand mining model}

\subsection{Model geometry}

A parametrised PFC model was developed to allow for simulation of mining under fill. Figure 5 illustrates the geometry of the model. A cross-section of a $35 \mathrm{~m}$ wide (HW to FW) and $30 \mathrm{~m}$ high stope was modelled. The walls of the stope had a $70^{\circ}$ dip. The undercutting of the stope was simulated by removing a predetermined length of the stope's floor.

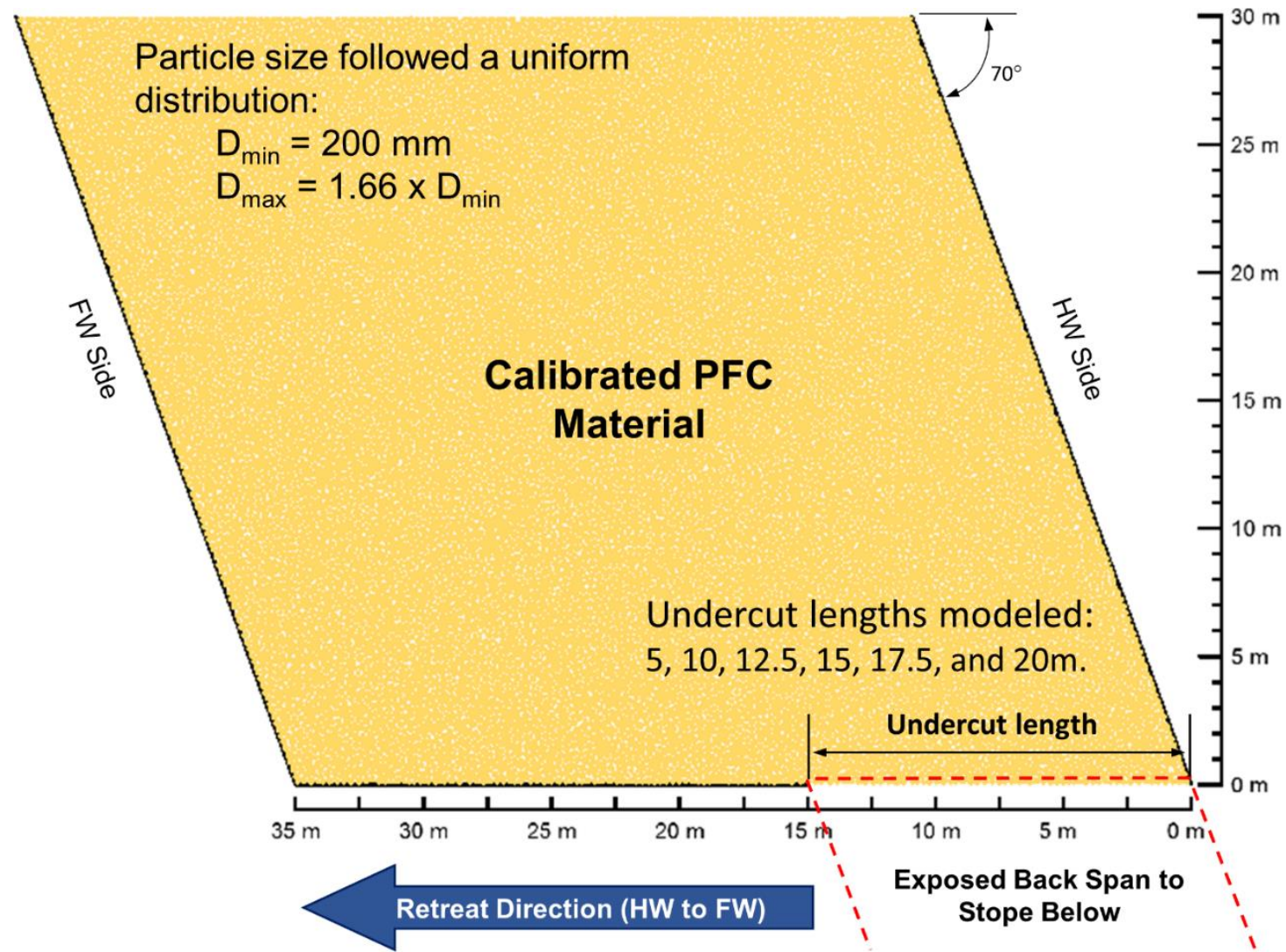

Figure 5 Geometry of the PFC stope model used for fill undercutting simulations 


\subsection{Simulation approach}

A simulation of a single case of CRF stability followed the methodology outlined in Table 3. The figures in Table 3 illustrate the conditions of the backfill and state of compressive forces within the stope (black lines) at various stages of the simulation.

Table 3 Methodology of a single stope undercutting simulation

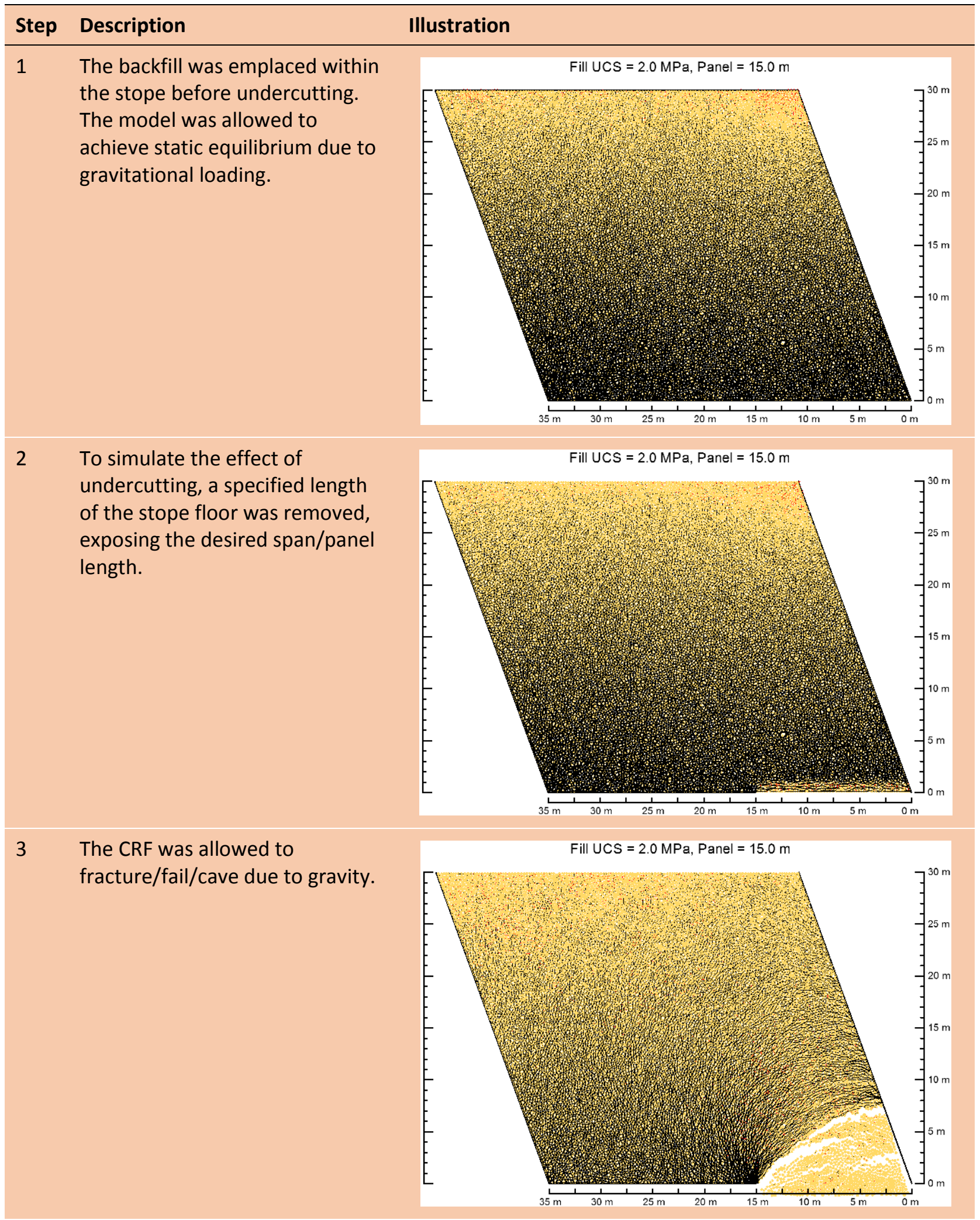


Table 3 Methodology of a single stope undercutting simulation (continued)

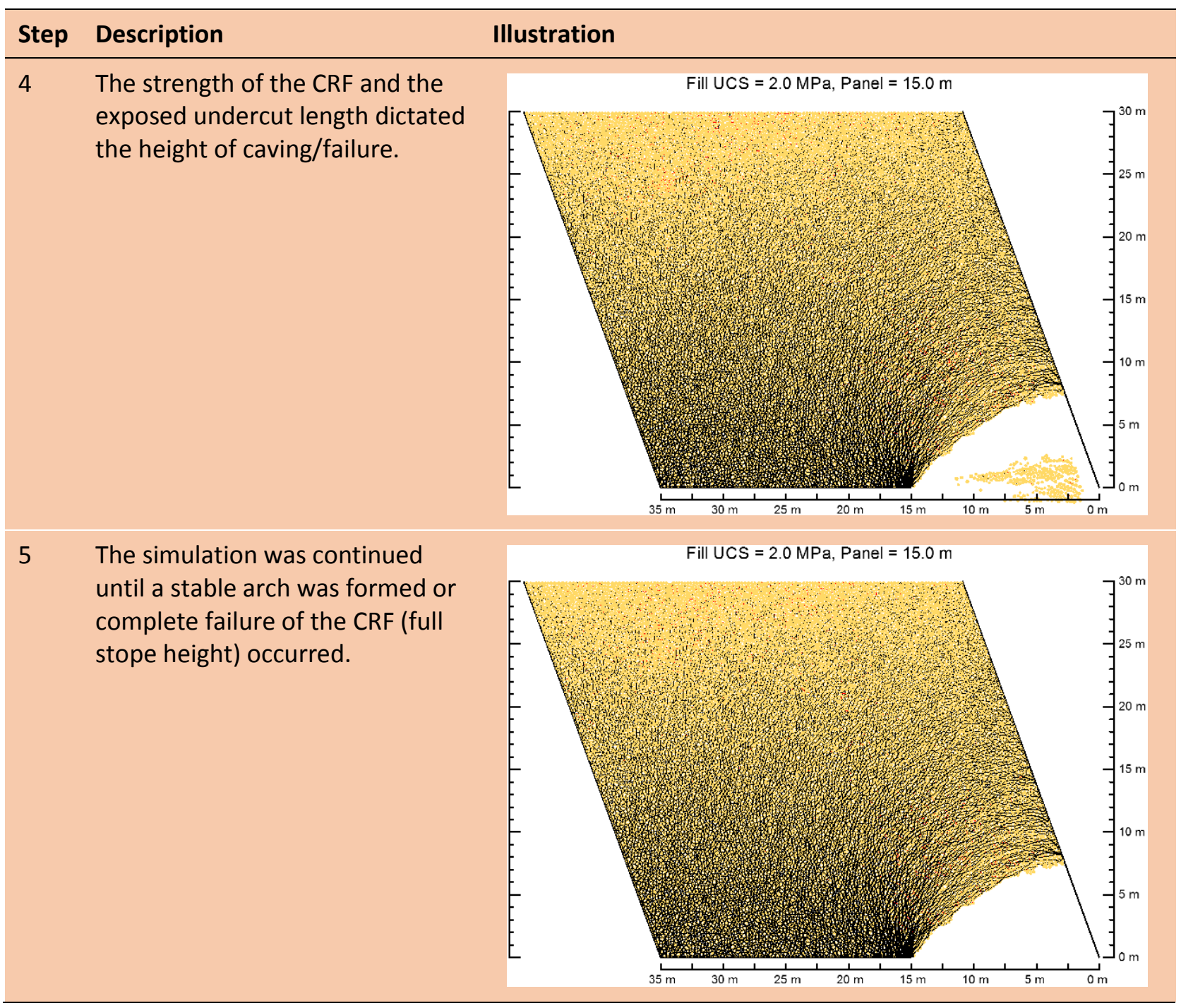

The stability of the fill in a stope with a certain undercut (panel) length was evaluated by running a series of models, each with a different fill strength. The evaluated fill strength values were incremented in $0.5 \mathrm{MPa}$ intervals and ranged between 0.5 and $6.0 \mathrm{MPa}$. The result of the simulation exercise was a matrix of undercut panel length and fill strength combinations. The result of a simulation was quantified in terms of a fill failure height.

When a PFC model is generated, particles are assigned initial positions randomly and their radii follow a uniform distribution governed by the specified minimum and maximum radii. Models, therefore, can be built having different particle arrangements. Two models with an identical set of micro-scale properties but differing particle arrangements will produce different (but not dissimilar) macro-scale responses. To account for variability in fill stability due to particle arrangement effects, three particle arrangement cases were investigated as part of this study. Each case was modelled using the outlined approach. This resulted in execution and evaluation of close to 100 PFC simulations. 


\subsection{Quantification of fill stability}

A PFC simulation was terminated once a stable arch was formed or complete failure of the CRF (full stope height) was achieved. In assessing the stability and performance of CRF, the height of failure ( $\left.h_{f}\right)$, or the maximum height at which the CRF achieved a stable arch, was recorded and expressed as a fraction of the undercut length (FUL). Both parameters are illustrated in Figure 6 . The FUL value is calculated by dividing $h_{f}$ $(6 \mathrm{~m})$ by the undercut length $(15 \mathrm{~m})$.

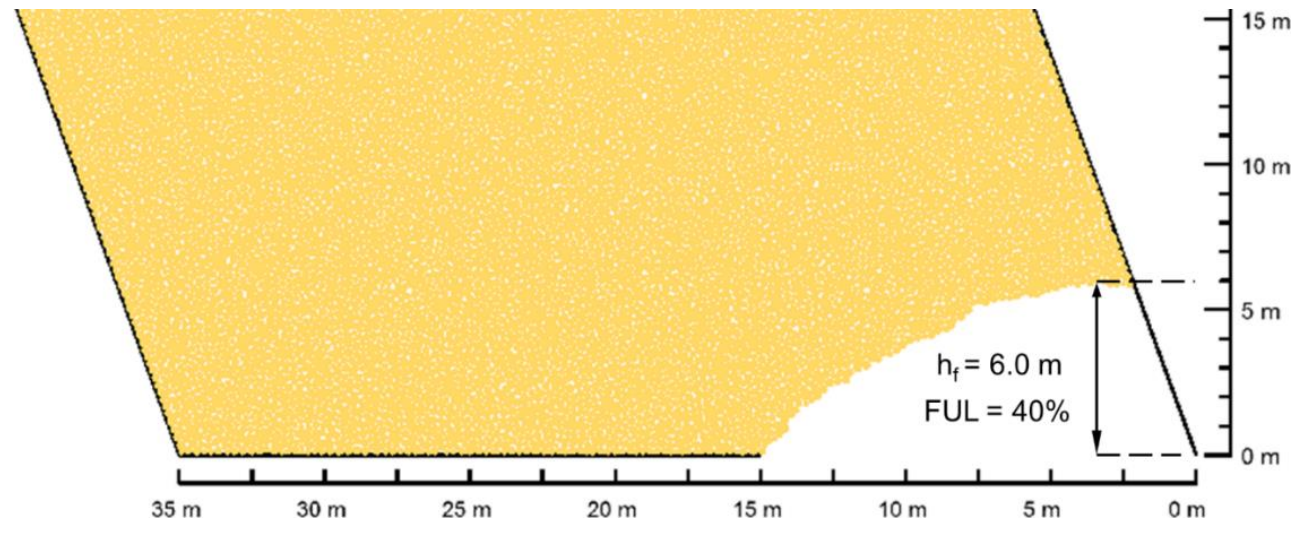

Figure 6 Definition of the height of failure $\left(h_{f}\right)$ and the FUL parameters

\section{$6 \quad$ Modelling results}

\subsection{Single case example}

Examples of four simulations of a $15 \mathrm{~m}$ long undercut for different fill strengths are illustrated in Figure 7. An identical particle arrangement was used in each of the four simulations shown. The results clearly illustrate that the height of fill failure decreases with the increase of the strength of the fill.

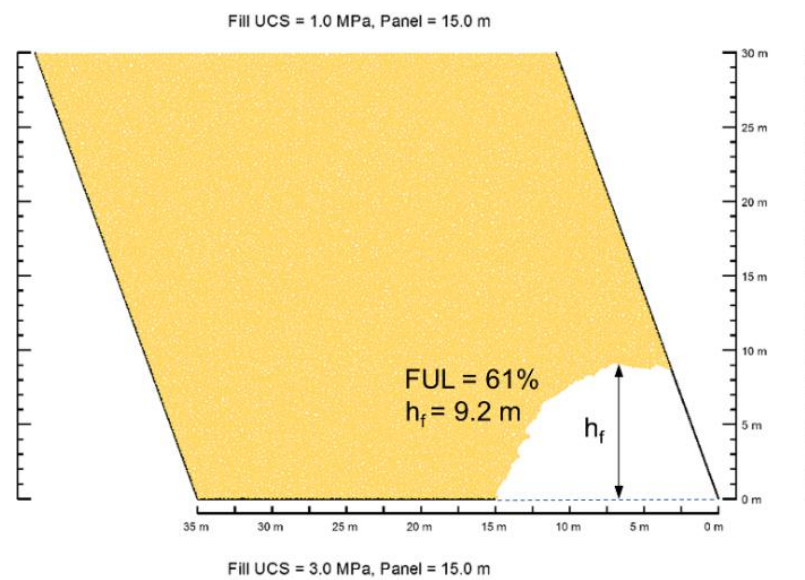

Fill UCS $=2.0 \mathrm{MPa}$, Panel $=15.0 \mathrm{~m}$
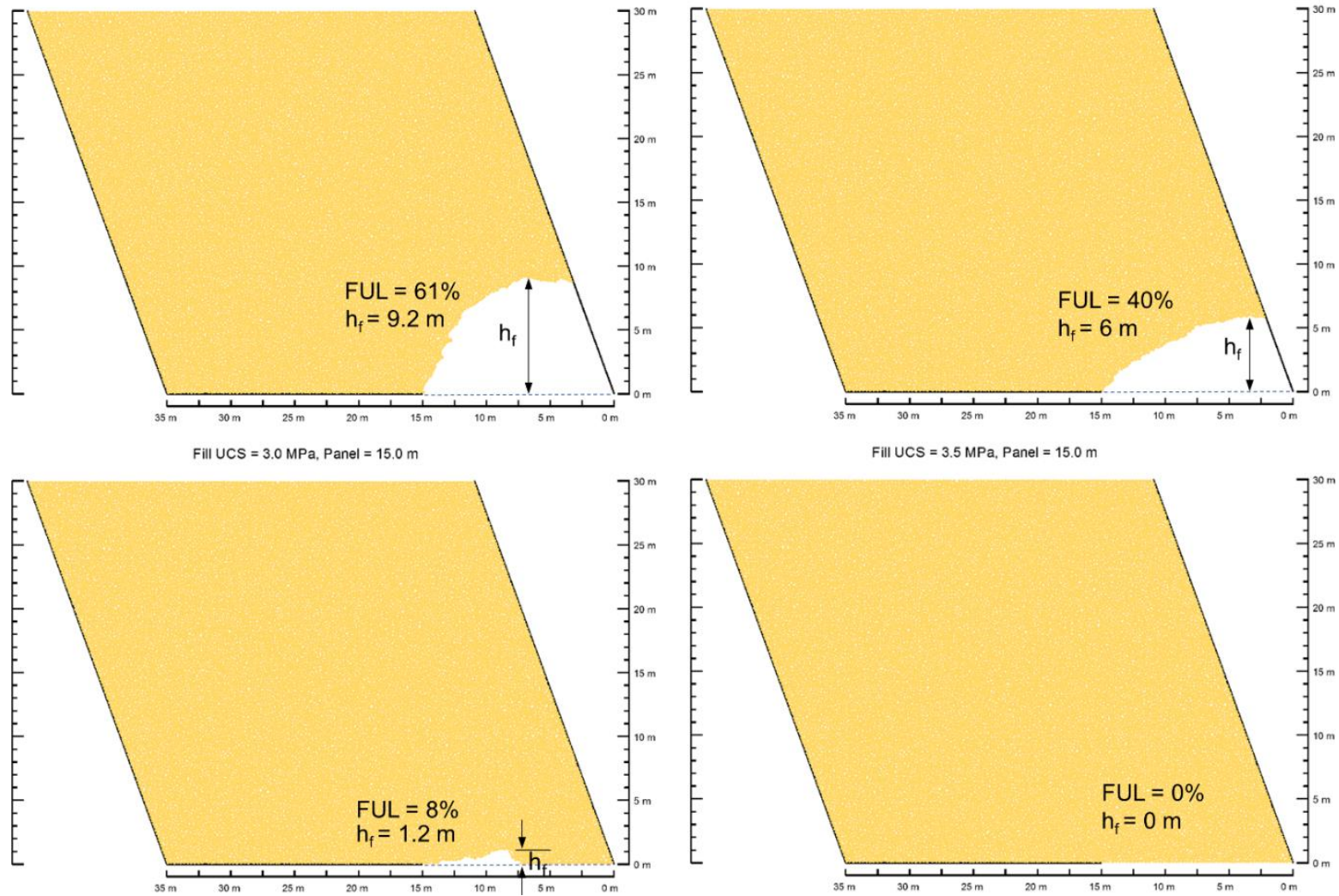

Fill UCS $=3.5 \mathrm{MPa}$, Panel $=15.0 \mathrm{~m}$

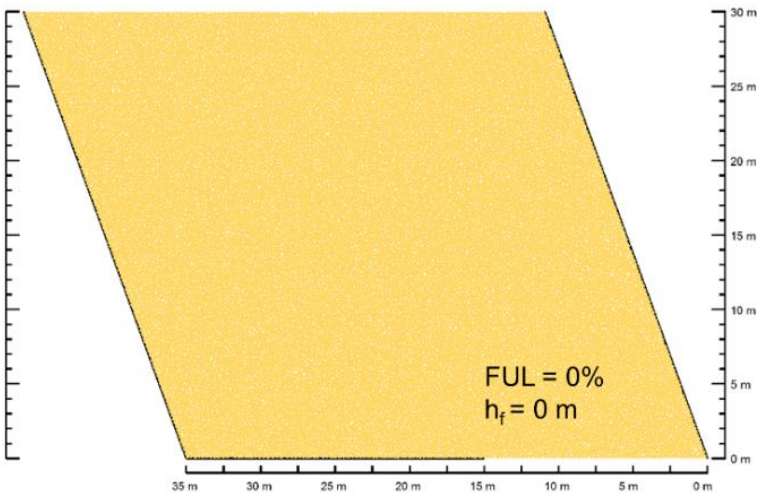

Figure 7 Example of simulation results for the case of a $15 \mathrm{~m}$ undercut panel 


\subsection{Variability}

Examples shown in Figure 8 illustrate results of three models that simulated undercutting of a $15 \mathrm{~m}$ undercut panel under fill with UCS of $2.5 \mathrm{MPa}$. The three models were based on different particle arrangements. It is demonstrated that for the analysed case, the height of failure may range between 1 and $7 \mathrm{~m}$ (mean of $3.5 \mathrm{~m}$ ) depending on the particle arrangement. A complete set of simulation results for a $15 \mathrm{~m}$ undercut panel is illustrated in the chart in Figure 8. This exercise was performed for each evaluated fill strength.

Fill $U C S=2.5 \mathrm{MPa}$, Panel $=15.0 \mathrm{~m}$

Fill UCS $=2.5 \mathrm{MPa}$, Panel $=15.0 \mathrm{~m}$
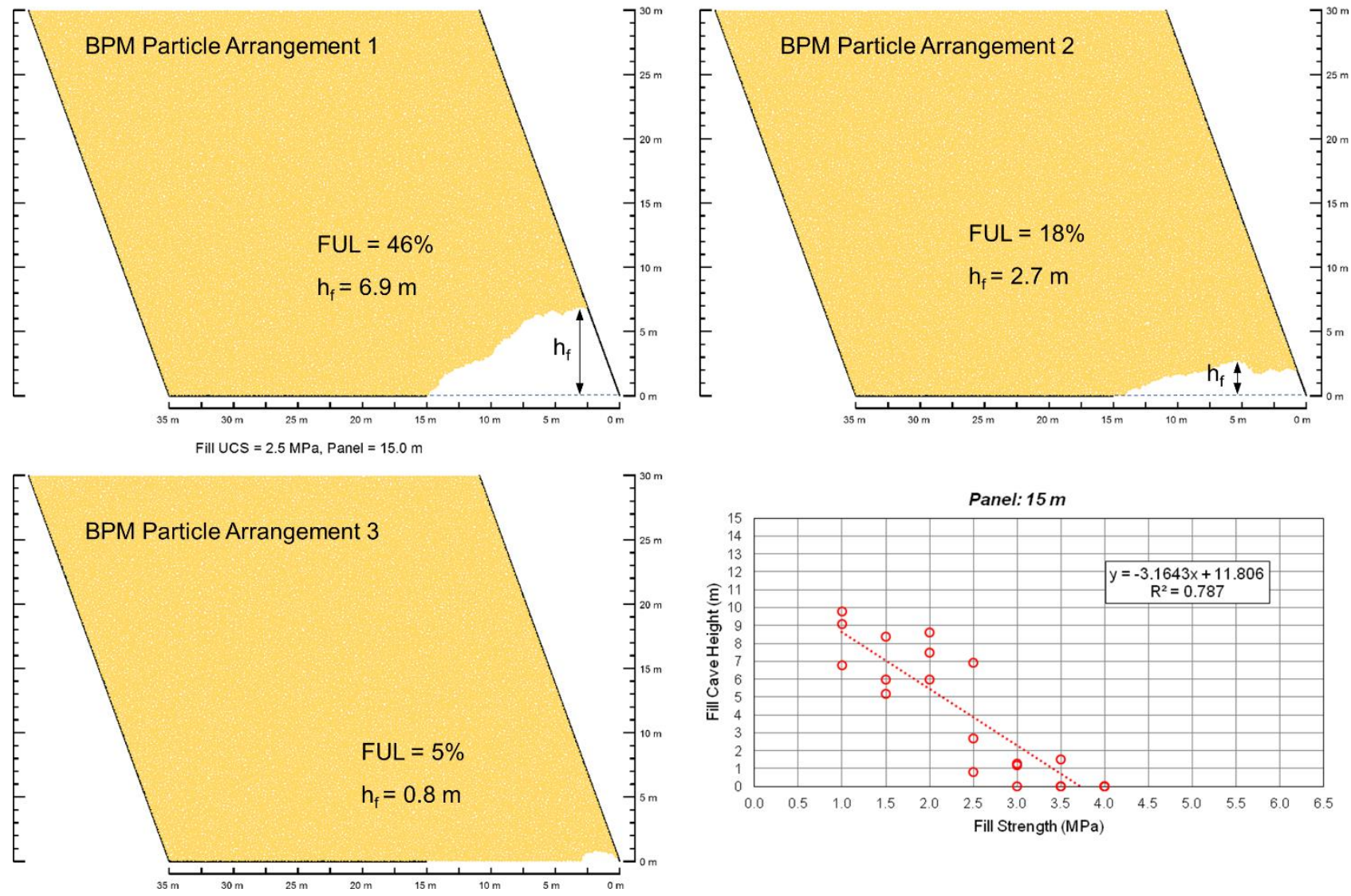

Figure 8 Illustration of variability in results between models with different particle arrangements for a stope filled with $2.5 \mathrm{MPa}$ fill and $15 \mathrm{~m}$ undercut panel, and a summary graph for all simulations for a $15 \mathrm{~m}$ undercut panel

\section{$7 \quad$ Design charts}

The results of all simulations were compiled into two design charts allowing one to estimate the degree of fill failure based on the size of the undercut and fill strength (Figure 9). The curves in the top chart of Figure 9 show the maximum height of the caved fill expressed as a fraction of the undercut panel size, the FUL parameter. The curves in the bottom chart show estimates of backfill dilution for an excavated stope (below) based on its size and fill strength. It was assumed that the width of the excavated stope was equal to the undercut panel width. Its height was $30 \mathrm{~m}$, identical to the one of the modelled stope. Backfill dilution was calculated in terms of volumes as follows:

$$
\text { Backfill Dilution }=\frac{\text { Failed Fill Vol. }}{(\text { Stope Vol.+Failed Fill Vol. })}
$$



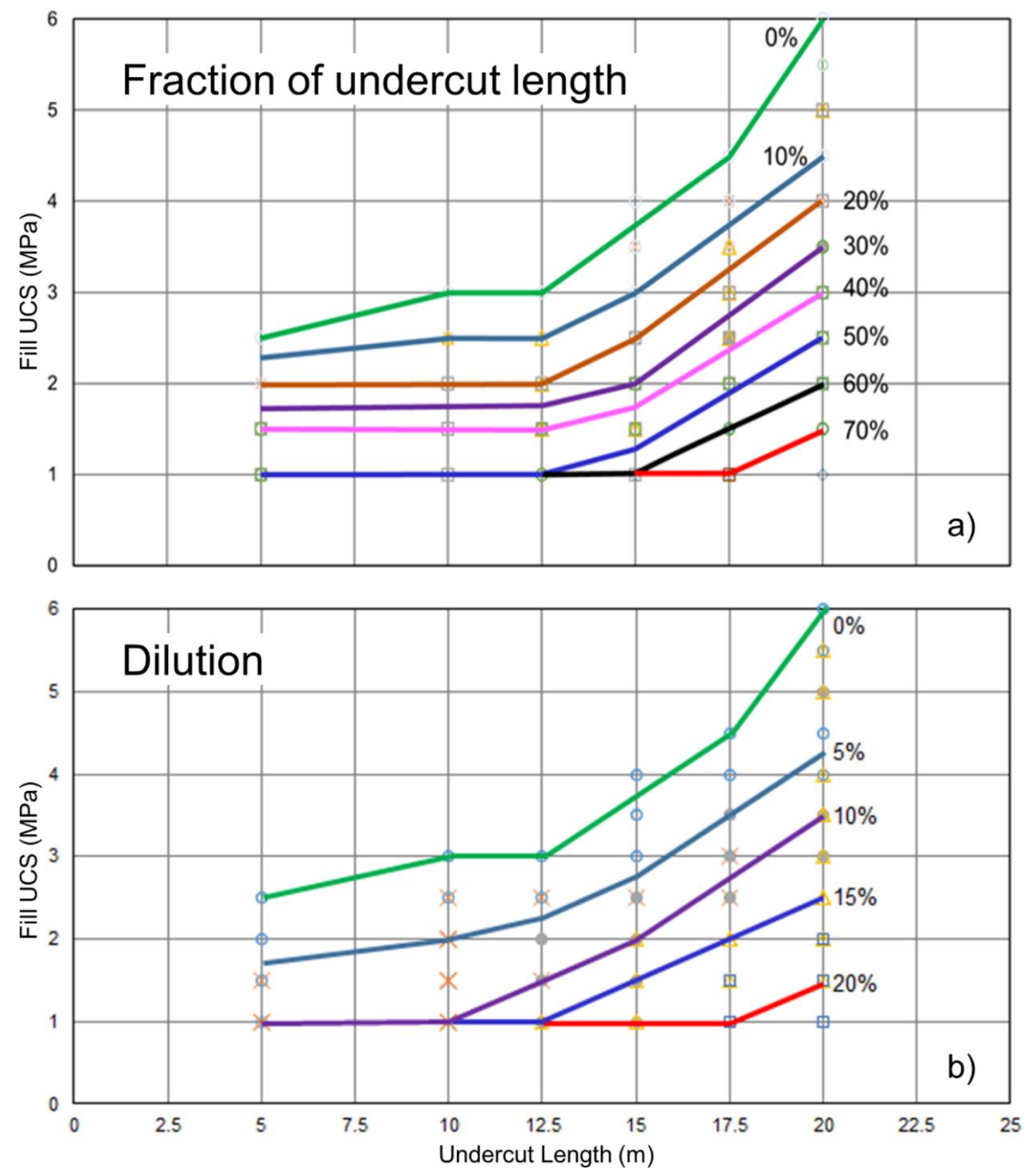

Figure 9 Design charts derived from the numerical simulations relating undercut panel size $(m)$ to the UCS of the fill ( $\mathrm{MPa})$. The curves represent the maximum height of caved fill expressed as (a) A fraction of the undercut panel length; and, (b) Dilution (b)

The charts allow the mining operation to make an informed decision regarding the stability of CRF, expected fill overbreak height and associated dilution. If the strength of the fill is known, one can estimate what the size of the stope below should be such that manageable overbreak and dilution conditions are met. Alternatively, given the size of the stope below, CRF strength requirements can be estimated to conform to accepted fill overbreak and ore dilution.

\section{Conclusion}

A study on the stability of CRF during undercutting at a base metal mining operation was carried out using numerical simulations. Innovative bonded particle modelling with flat joint contacts was used to simulate fill stability for a range of undercut sizes and fill strengths. The simulations provided results which were easy to interpret. The results of the simulations were combined to produce design charts to help the mining 
operation in relating the width of the undercutting panel, fill strength, and associated fill overbreak or ore dilution.

\section{Acknowledgement}

The authors gratefully acknowledge Dr David Potyondy of Itasca Consulting Group in Minneapolis, USA, for his help with the use of the PFC code.

\section{References}

Annor, AB 1999, 'A study of characteristics and behaviour of composite backfill material', PhD thesis, McGill University, Montreal. Brummer, RK, Andrieux, PP \& O'Connor CP 2003, 'Stability analyses of undermined sill mats for base metal mining', in RK Brummer, PP Andrieux, C Detournay \& R Hart (eds), Proceedings of the 3rd International FLAC Symposium, A.A. Balkema, Rotterdam.

Itasca Consulting Group, Inc. 2014, Particle Flow Code in 3D, version 5.0 software documentation, Itasca Consulting Group, Inc., Minneapolis.

Itasca Consulting Group, Inc. 2017, Particle Flow Code, Itasca Consulting Group, Inc., Minneapolis, viewed 21 July 2017 , http://www.itascacg.com/software/pfc

Lafarge 2012, Results of laboratory UCS tests on CRF samples, internal report, unpublished.

Mitchell, RJ 1991, 'Sill mat evaluation using centrifuge models', Mining Science and Technology, vol. 13, no. 3, pp. $301-313$.

Pakalnis, RT, Caceres, C, Clapp, K, Morin, M, Brady, T, Williams, T, Blake, W \& MacLaughlin, M 2005, 'Design spans - underhand cut and fill mining', Proceedings of the 107th CIM-AGM, Canadian Institute of Mining, Metallurgy and Petroleum, Westmount.

Pakalnis, RT \& Hughes, PB 2011, 'Sublevel stoping', in P Darling (ed.), SME Mining Engineering Handbook, 3rd edn, Society for Mining, Metallurgy, and Exploration, Englewood.

Pierce, M, Potyondy, D, Andrieux, PP \& Lessard, J-S 2002, 'Use of the Particle Flow Code (PFC2D) to assess stability of undercut rockfill at Brunswick mine', in R Hammah, W Bawden, J Curran \& M Telesnicki (eds), Proceedings of the 5th North American Rock Mechanics Symposium and the 17th Tunnelling Association of Canada Conference, vol. 1, University of Toronto Press, Toronto, pp. 173-180.

Potyondy, DO \& Cundall, PA 2004, 'A bonded-particle model for rock', International Journal of Rock Mechanics and Mining Sciences, vol. 41, no. 8, pp. 1329-1364. 